Open Access

\title{
Underscoring the value of video analysis in multilingual and multicultural classroom contexts
}

Sara E. D. Wilmes, ${ }^{*}$ Roberto Gómez Fernández, Anna Gorges and Christina Siry

\author{
* Correspondence: \\ sara.wilmes@uni.lu \\ Institute of Applied Educational \\ Sciences, University of Luxembourg, \\ Maison des Science Humaines, 11, \\ porte des Sciences, L-4366 \\ Esch-sur-Alzette, Luxembourg
}

\begin{abstract}
This article presents multiple episodes drawing from three distinct research projects conducted in multilingual classrooms in Luxembourg, to underscore the value of video analysis in culturally and linguistically diverse classroom contexts. We show how video analysis that valorizes the non-verbal in interaction has the ability to reveal communicative resources often masked by analysis rooted in the verbal. From the examples presented, that span teacher and student interactions in both elementary and secondary classrooms, we make a methodological argument based on analytical approaches utilized in all three research projects to demonstrate how we have come to an expanded notion of voice in our research that is revealed through multimodal video analysis. Specific analytical approaches that illuminate the embodied and multimodal aspects of voice are discussed. We conclude by underscoring the benefits of embodied and multimodal approaches to video analysis for research with all students, but most importantly for students often marginalized through analytical approaches that prioritize the verbal. Finally, we discuss the implications of video research that works to highlight resource-rich views of teaching and learning across learning contexts.
\end{abstract}

Keywords: Classroom video analysis, Multilingual contexts, Culturally and linguistically diverse students, Science education, Embodied, Multimodal

\section{Background}

The value of digital video as a data source and research tool in educational contexts is widely recognized (see for example Derry et al. 2010). For a majority of researchers working in classroom contexts, and across a wide spectrum of theoretical orientations, the use of video and video analysis is a given. The advent of digital video recording, and the development of technologies that allow researchers to quickly and easily capture events on video, and store large volumes of video, has revolutionized the way researchers work. Yet, research articles that directly underscore the value of video approaches in our research context, specifically an examination of students' communicative resources in science education in culturally and linguistically diverse classrooms, are few-and-far-between. Thus, our goal in the work we present here is to contribute to the research literature that valorizes the use of video analysis in multilingual classroom contexts by drawing across our individual studies to make collective claims

(c) The Author(s). 2018 Open Access This article is distributed under the terms of the Creative Commons Attribution 4.0 International License (http://creativecommons.org/licenses/by/4.0/), which permits unrestricted use, distribution, and reproduction in any medium, provided you give appropriate credit to the original author(s) and the source, provide a link to the Creative Commons license, and indicate if changes were made. 
about the value of looking beyond the spoken and written to understand students' meaning-making in science.

More specifically, in this article we draw from three research projects in our multilingual national context to illustrate the uses and potential of video analysis (e.g. Wilmes 2017b; Gómez Fernández and Siry, 2018). We will show how using video analysis to examine the embodied and multimodal engagements of students and teachers brings a richer view of communicative, interactive resource useage and thus allows us to see and hear the voices of students who are often marginalized because of lack of proficiency in the sanctioned classroom language(s). This is important for research conducted across a range of educational contexts and is even more crucial for research with students who are developing proficiency in classroom-sanctioned languages.

\section{Theoretical perspectives}

Our work is rooted in sociocultural views of classrooms and learning (e.g. Tobin 2012). As such, we draw upon theoretical perspectives that recognize that learning is mediated by interactions that have social, material, temporal, historical, and social components (Tobin 2012; Wertsch 1994), and that allow us to theorize and explore the nature of classroom interactions in their social and cultural contexts. Additionally, we situate language use among actors in sociolinguistic theories of language as action and practice (Moyer 2008). We pose research questions and adopt methodologies that allow us to explore the contextualized, process-oriented, nature of communication in different learning contexts.

We root our analysis of communication in sociolinguistic theories of language use and communication. Our work views language as a social practice that unfolds in interaction in contextualized, interactive and hybrid ways (Cameron et al. 1992; Creese 2008). Language is but one of many communicative resources that actors use and employ in the processes of relating to each other and to the world. These processes are never neutral. The theoretical perspectives we draw from support our examination of communicative resource use in interaction toward our goal of working to understand power relations in classrooms and their connection to wider societal processes.

\section{Video analysis in multilingual classroom contexts}

Given the availability and affordability of digital recording equipment and data storage options, education research projects often incorporate video data. The advantages of video as a data source are multiple and include the ability to capture a multitude of factors related to learning contexts that include aspects of interactional, environmental, and spatio-temporal contextual factors (Moyer 2008). Being able to replay events in a classroom at different points in time, and also at different speeds of replay (e.g. at one tenth of one second), supports a focus on participants' interactions, and allows for examining moments that may have passed unnoticed in the complexities of classrooms on the scale of minutes (Ali-Khan and Siry 2014).

Through our work, which encompasses research in multilingual classrooms across a wide span of ages and grade levels, we have repeatedly witnessed the value of video analysis. When coupled with theoretical frameworks that decentralize the verbal, it has the power to reveal more than the spoken and to widen views of classroom interaction (e.g. Gómez Fernández and Siry 2018; Wilmes and Siry, in press). This has allowed us 
to refocus our methods in ways that incorporate both the verbal and more importantly, the non-verbal in classroom interactions. It is often these non-verbal forms of interacting that receive less attention, or that are shifted to secondary or supporting roles in analyses. In our research in the field of science education, we intentionally keep them in the forefront. This has allowed us to expand notions relevant to our theoretical frameworks, such as the notion of voice, in ways that incorporate both the verbal and the nonverbal. Our research projects thus explore voice in ways that reveal diverse communicative resource use in multilingual contexts, as we elaborate in the next section.

\section{Notions of voice in education research}

In the past, voice has been used to signify many different aspects related to education, pedagogy, and research in education. In our work in general, and in this manuscript in particular, we define voice as the ways in which a person communicates and what he or she communicates in/through interaction. In other words, in our research we begin with voice as a synonym for talk, but then through the use of video analysis coupled with multimodal theorizations of voice, expand this to include what is communicated through all resources employed, not just the verbal. In this way, we arrive at an expanded interactional view of voice, which we are then able to relate to the social, cultural, political, and historical context in which this voice is contextualized. Thus, we orient our work toward conceptualizations and theorizations of voice that are interactional and occur in conversation, and that have political and historical meaning in classroom contexts.

Our research, which spans over a decade, collectively has focused on examining the ways in which students and teachers interact in culturally and linguistically diverse classroom contexts, and how this relates to equitable educational opportunities (see for example Wilmes et al. 2018). In the context of science education, we examine spaces created through inquiry-based pedagogical approaches for student voice (e.g. Wilmes 2017a), as well as how student voice can be used as methodology through photoelicitation (e.g. Ali-Khan and Siry 2014) and through participatory approaches to curricula (e.g. Siry and Max 2013).

In this article, we present three episodes to illustrate how we have incorporated methods that lead to an expanded notion of voice-in-interaction. After the elaboration of the episodes, we turn to a discussion of voice and how embodied and multimodal approaches to video analysis can highlight aspects of voice not revealed through analytical approaches that prioritize the spoken.

\section{Turning toward embodied and multimodal notions of voice}

We theorize human interaction in general, and interaction in classroom contexts in particular, as situated, evolving from discourse-in-interaction, and mediated by the resources that agents, in this case students and teachers, utilize as they participate in meaning making events (Kress et al. 2001; Siry et al. 2012). Multiple and varied communicative resources, including gaze, position, gesture, as well as additional embodied and material resources, are integral to communication and understanding in classroom contexts (Hwang and Roth 2011; Norris 2004). Through different combinations of these semiotic resources, people orchestrate meaning, and in doing so, draw upon 
nonverbal as well as verbal resources (Jewitt 2009; Kress et al. 1998). Multimodal research approaches have established the importance of modes other than the verbal in the context of interaction and learning in general, and in science classroom contexts in particular (Kress et al. 2001; Hwang and Roth 2011). Research that explores embodiment, particularly through the use of multimodal methodologies, can reveal understandings of how learning and interacting are connected. As we will elaborate in the discussion section, this can lead to further understandings as to how to create spaces for effective pedagogies that build on the embodied nature of learning and that view all students through resource-rich (Siry 2011) lenses.

Prioritizing the spoken and written aspects of science learning does not present the whole human complex of communication and engagement in science classrooms (Jaipal 2010). In this paper, we present three episodes of student engagement in science lessons and demonstrate how analytical approaches that incorporate video analysis in conjunction with embodied and multimodal theorizations of voice, can provide more robust view of students' engagement in science practices as well as their science-related understandings, in particular in culturally and linguistically diverse classrooms.

\section{Our multilingual research context}

We currently and collectively conduct research in educational contexts in Luxembourg. Geographic, historical and cultural factors have led to the designation of Luxembourg as an officially trilingual country (Luxembourgish, German, French). Accordingly, Luxembourg's national primary school policy focuses on students being taught in and using these three languages for content instruction. At the completion of secondary school students are expected to be fluent in all three. To support students in this goal, $44 \%$ of instructional time at the primary level is dedicated to learning languages. This is the highest percentage in Europe, followed by Malta with 14.9\% (European Commission/EACEA/Eurydice 2017). One of these languages, German, is stipulated by the national curriculum documents as the main language for the teaching and learning of science at the primary level (MENFP 2011). At the secondary level science is either taught in German or French according to the program of study.

Adding to the linguistic diversity stipulated by a trilingual national curriculum, the country has the highest density of non-national residents in Europe. Most of these nationalities are European, the highest percentage being from Portugal or having a Portuguese-immigrant background. Luxembourg's super-diversity (term borrowed from Vertovec 2007) is reflected in its public schools. Almost half of the student population (43\%) holds a nationality from a country other than Luxembourg (MENJE 2017). The diversity is such that students speaking language(s) other than Luxembourgish at home are the majority. In primary school, for example, the latest data available indicates that 63\% of children have languages other than Luxembourgish as a first language (MENJE 2017). This means that an extremely high proportion of students learn science through a second or third language, and thus a language that is not spoken at home, a trend that continues through secondary school. This linguistic and cultural diversity has been at the root of our research regarding the use of language, communicative resources, and voice in science classroom contexts. It has led to our realization of the value of video analysis to research interactions and learning in these environments. Further, this diversity 
has led us to question our assumptions regarding language and voice in classrooms, and through this questioning, to in turn question how we conduct video analysis.

\section{Methods: Turning the sound off: Video analysis in multilingual classrooms}

The methodological argument we present in this manuscript is supported by analysis drawn from three distinct research projects we conducted in Luxembourg over the past five years, each of which utilizes video analysis, but with slightly differing approaches and foci. The data sources and analytical approach for each vary slightly, thus for the episodes we present next we briefly detail how these video analysis methods contributed to rich and robust views of voice in classrooms. For each, extensive video data was collected in addition to other multi-layered data (such as student interviews and student artifacts). This diversity of data resources allowed for multiple perspectives on the video data (Elmesky 2015). The episodes we present herein were purposefully selected to illustrate embodied interactions that became evident when we backgrounded the verbal in analysis. Through a presentation of these episodes we will underscore key points that arise when the embodied and the multimodal are prioritized in such video research analytical processes.

Our cross-cutting approach to video analysis was used in all three of the episodes presented to explore the resources employed in interaction and communication. Common to the three projects from which these episodes were selected was an analytical process that incorporated at least one phase of analysis with the sound off in order to examine moment-to-moment the embodied, multimodal, non-spoken interactions and reveal communicative resources that are often backgrounded in education contexts.

\section{Example 1 - embodied discussion with a teacher}

The first episode we present took place in the context of a primary school research project that explored student-driven inquiry-based science learning about the topic of evaporation and condensation in a multilingual primary classroom. ${ }^{1}$ The data sources collected were extensive and, in addition to classroom videos, included student science journals, research team conversations, and student and teacher interviews. This allowed for viewing phenomena that emerged in video analysis through multiple layers of understanding. Video data were collected using two sizes of digital cameras. Full-sized cameras were positioned to capture the entire classroom from two different, complementary angles. Additionally, smaller cameras were placed on tabletops next to each student group. This second set captured close-up views of students' and teachers' conversations, movements, and interactions.

Video analysis incorporated several aspects to analyze multiple modes of interaction (Erickson, 2017). Most relevant to the claims we set forth in this article is that an initial video analysis took place with the sound off. This moment-to-moment view of the non-verbal components of students' and teachers' interactions provided insight into the positions, movements, forms of interactions, and meaning-making that occurred in ways that were often masked, overlooked, or subordinated to the verbal when working with the sound turned on. Additional rounds of analysis and transcription followed and layered on verbalizations along with multi-modal facets of interaction.

The first episode we present involved a class of ten- to eleven-year-old students who were provided with everyday materials to design science investigations. The episode occurred on 
students' third day of investigation, when small-groups were designing and conducting investigations to answer students' questions about condensation. A group of three students had just finished conducting their investigation when the teacher approached the group and asked What happened here? while pointing to the plastic containers students had assembled to investigate condensation formation and water movement. It is important to explain that $\mathrm{Zach}^{2}$ is a non-native speaker of German, the language of science instruction in this class. Zach, shown in video offprints in Fig. 1, had been working with two other students in a small group, speaking Luxembourgish, when the teacher approached. The teacher addressed them in German, and the students responded to the teacher in German. It was revealed through student focus group interviews that for these three students, German was not one of the languages they speak at home, nor was it a language that they would spontaneously choose to speak together.

In response to the teacher's question, Zach points to specific locations on the materials in front of him, as he describes the location of warm water and its movement. He uses indexical gestures (Goldin-Meadow 2005) to point to the movement of water through the set-up showing that the water started in the top chamber (Fig. 1).

As he pointed (A-D) he began to say ...ehm... multiple times, and then his rate of gesturing in the air increased $(\mathrm{E}-\mathrm{H})$ as has been shown to occur when one is working in a non-native language (Ramos and Espinet 2013). Zach next shifted his gaze away from the teacher (from left to right) and placed his hand to his mouth $(\mathrm{H})$. This use of a thinking face and gesture, coupled with a pause in speech indicate that Zach was using what is referred to in the literature as stalling behaviour, as he searched for his next verbalization (Dörnyei and Kormos 1998). Through this assemblage of embodied actions and verbalizations over the course of several minutes Zach recalled the word melts (I). This specific information about the location and movement of water was not conveyed through Zach's verbal expressions alone. It is only by considering the multimodal assemblage of resources he used in his

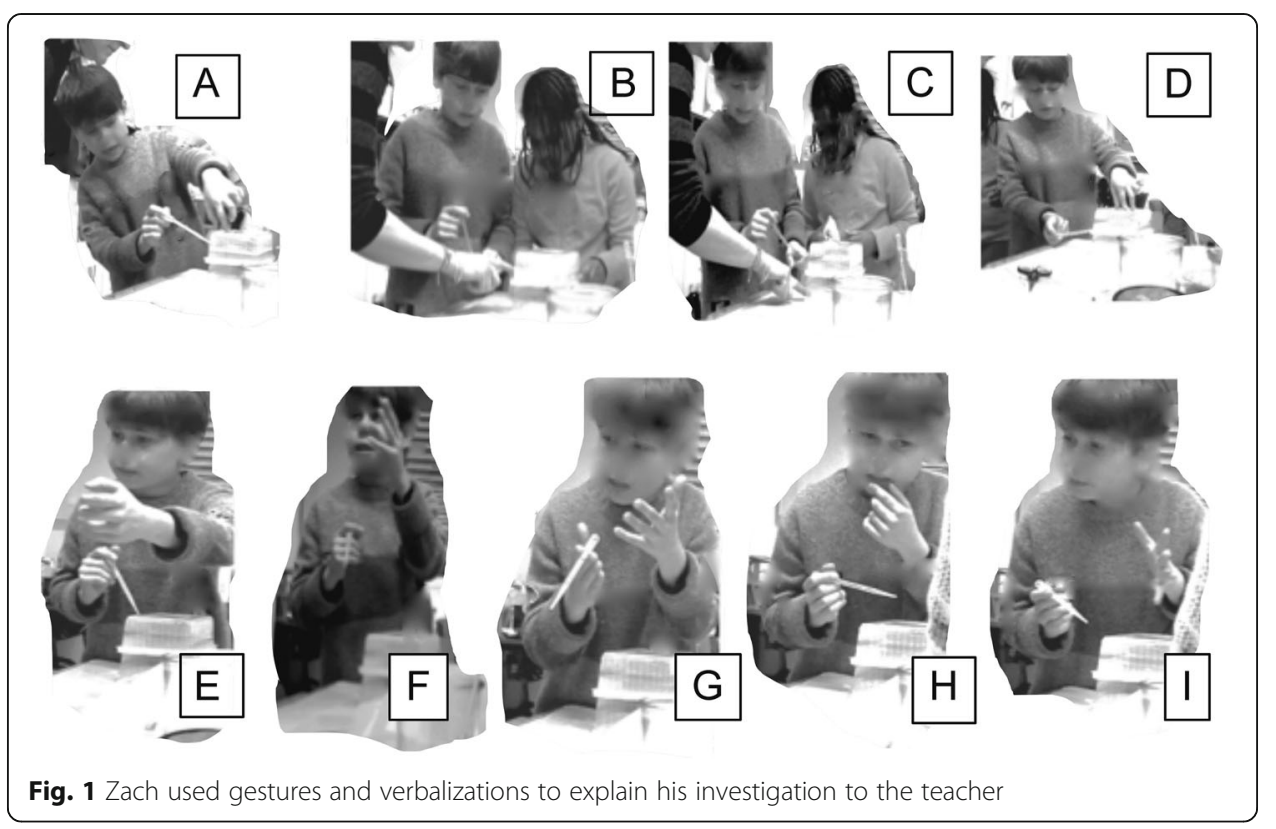


response to the teacher' question that what he investigated, and the result, became clear.

Example 2 - Joâo's embodied involvement during a hands-on activity with a water filter The following episode is drawn from a second study involving video ethnography in a classroom with 8-9 year-old children. ${ }^{3}$ Our ethnographic research aims to better understand the use of participatory approaches in the teaching and learning of sciences: "participatory approaches to teaching, learning, and research can allow science to be emergent from children's interactions with each other in open-ended situations" (Siry 2013, p. 36). Following a "bricoleur" approach (Lévi-Strauss 1966) we collected a myriad of data (e.g. classroom video-recordings, classroom audio recordings, interviews, artefacts, field notes) which allowed for methodological triangulation (Denzin 1970). To assure trustworthiness and authenticity of the study (Lincoln and Guba 1985), we utilized data triangulation, investigator triangulation and theoretical triangulation.

One of the children in the class, alias "Joâo" (Fig. 2, shown in a striped shirt in the upper left-hand corner), is Lusoburguês, meaning a Luxembourg-born and educated child with a so-called hybrid identity, being culturally, linguistically and nationalitywise both Portuguese and Luxembourgish. Joâo belongs to the ethnolinguistic minority of children that have a Portuguese-immigrant background, the largest minority group in Luxembourgish schools, who according to statistics are an under-performing group in science (OECD 2018).

The second episode that we present is from one lesson extracted out of a series of five on environmental education that focused on the water cycle. During this fourth lesson, there were four stations students moved among. The following video episode focused on Joâo and his group's investigation at one of the four stations, devoted to a water filtering activity. Joâo's participation in this lesson has been analyzed in a previous paper (Gómez Fernández and Siry 2018), in which we drew on Goffman's (1981) notion of footing to illustrate his sudden change of participation. Goffman (1981) states that "a change of footing implies a change in the alignment we take up to ourselves and the others present as expressed in the way we manage the production or reception of an utterance" (p. 128). This change of alignment was visible in the beginning of the science investigation, as it became evident through video analysis that Joâo distributed the materials and group task among his group members. In doing so, he acted as the leader of the group.
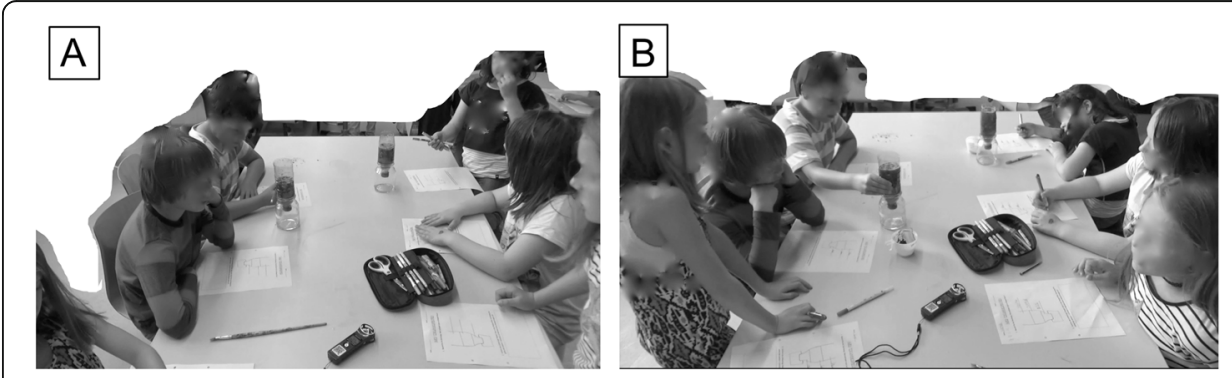

Fig. 2 Joâo's embodied engagement in a water filter activity 
Herein we build upon these previous findings to turn our attention to how video analysis enhanced our understandings. Analysis revealed that Joâo's embodied participation during this activity was strikingly different from his participation at other stations, which did not include manipulation of an artifact. In our examination of prior moments of his interactions at other science stations captured on video, Joâo seemed to passively engage in the different tasks, especially those that included writing and/or speaking German. Our analysis focused on the ways in which Joâo's participation shifted through his embodiment in the activity, as evident in the video recordings (see Gómez Fernández and Siry 2018). Drawing upon this previous work enables us to elaborate how analysis foregrounded the nonverbal and to explain how this in turn grounded claims about his embodiment in science investigations.

The group of children highlighted in this example determined their roles in the experiment on their own when they arrived at the station. Through recursive, iterative video analysis of this episode, we were able to zoom into Joâo's interactions and notice a change in his participation and embodiment over the course of the investigation which was remarkable and sudden. As can be further seen in the video, Joâo was also the first one to consider a worksheet that the students were meant to complete, while his other colleagues were still distributing these worksheets. However, analysis revealed that when Joâo was confronted with the task of writing the results of the investigation in German on the worksheet, he needed to copy from his peers, and as such changed footing and role quickly, and thus again became a peripheral member of the group.

During this activity, Joâo was not able to use his home language (Portuguese) as a resource, as the other children in his group defaulted to a use of Luxembourgish. Thus, he was less verbally engaged than his peers in his group. However, through video analysis we saw how during the active investigation with the water filter, Joâo underwent a sudden change of participation. By focusing analysis on the nonverbal interactions of the group of students, it was revealed that Joâo copied notes from his classmate to complete the worksheet (Fig. 2A), illustrating his more peripheral role when his task was focused on writing. However, Joâo's leadership resumed when he finished copying the notes of his partner, and once again engaged in further nonverbal investigation with the water filter (Fig. 2B). In this particular study, alternating between viewing and analyzing videos with the sound on, as well as off, provided a lens onto the complexity of Joâo's interactions and revealed significant changes in his footing as he was able to participate in the science investigation without relying on spoken words.

\section{Example 3 - embodied explanations about sustainability}

The third example comes from a study conducted in a secondary school that aimed at highlighting the importance of resource rich approaches to science learning in multilingual classrooms. In order to conduct a video-ethnographic study (Pink 2002), both video and audio material was collected. Video was recorded with three fixed cameras that captured each of three group tables. Audio was recorded with individual audio recorders for every student, to be able to zoom into individual conversations. Individual interviews with the students were conducted at the end of the project, which revealed further insights in the usage of languages. 
The data stems from a classroom project about sustainability, which was conducted at an alternative high school where students aged 16-30, who dropped out of the traditional school system, have the chance to gain a leaving certificate. The project aim was for students to construct a poster about notions of sustainability in small groups in order to present the same at a mini research colloquium at their school. A multimodal data analysis approach was used (Kress 2009). Videos were watched with the sound on as an initial step to identify relevant vignettes showing science learning happening in multiple ways. The sound was then turned off and on in different rounds of video viewing in order to identify focal students. Since both viewpoints, with the sound on and with the sound off, provided differing lenses to examine the interactions, each led to different initial observations as to which aspects might be interesting for further analysis. Thus, it was at the interface of both of these viewpoints, with the sound off as well as on, that a fuller picture of what was happening could be obtained. The chosen vignettes were then multimodally transcribed, drawing on both videos as well as individual audio recordings, and these together were then used for in-depth analysis.

A majority of students in this class had a linguistic repertoire consisting of more than three national languages. Two of our authors were acting as supporting teachers in the video-recorded class, and they, as well as the classroom teacher, encouraged the use of students' full linguistic and semiotic repertoires for meaning making during the observed lessons. However, the school languages are German and French, which is why the students' posters had to be either in French or German. This third episode we present occurred during a round of questions after the final poster presentation of one culturally and linguistically diverse student, alias "Sandra" and her group. Sandra had a linguistic repertoire of seven languages, and during the production of the poster, she was making sense of the topic in multiple languages by translanguaging, which refers to the smooth use of elements from different named languages (García 2009). However, on the day of the presentation, she was asked to explain her topic of investigation in German, which is her (and most other students' of this class) weakest school language. Sandra spoke to her audience about water extraction in Africa. In that context, she talked about land grabbing, which is the deprivation of land from local farmers by big companies.

Sandra first talked about the lack of landownership papers among the farmers. While she was taking in German (indicated with an underlined in the text that follows), she would smoothly move to speak in Luxembourgish (indicated in bold italics), which is often the langauge of communication between students in Luxembourg. "Eh, people had no rights, rights eh- Because they have no- no papers." showing a flat hand and a

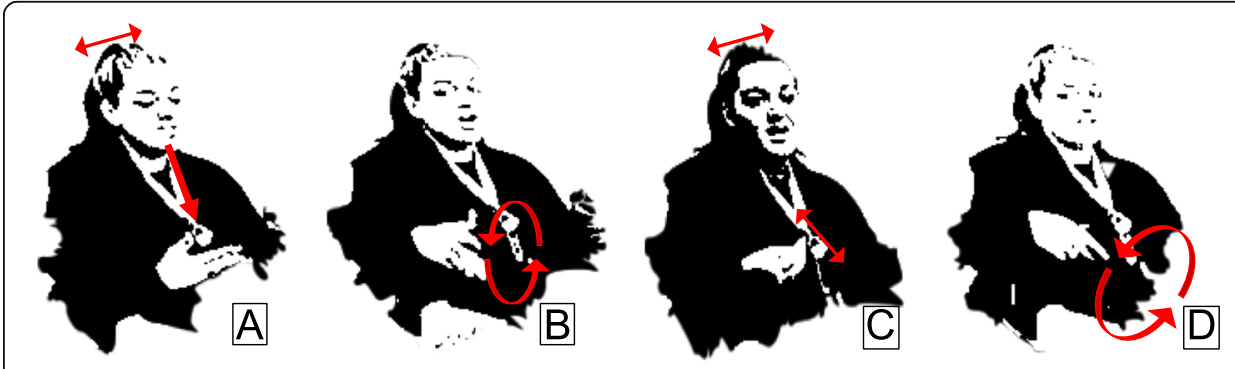

Fig. 3 Sandra's embodied explanation of land grabbing during a discussion about water extraction 
shaking of her head (Fig. 3A). She made a repeating circle movement of her hand to demonstrate that the situation had been ongoing and said: "They had- It has been that way for a long time and-" (Fig. 3B). Then, she shook her head again saying: "And eh- They cannot prove any- any- anything" to emphasize the lack of hard proof, which she symbolized with an up- and downwards movement of her hand with all of her finger tips touching the tip of her thumb (Fig. 3C). Then she drew the borders of a territory in the air saying: "that these are their territories" (Fig. 3D).

All of the students in the group were plurilingual, which means that they all have different levels of proficiency in the various languages of their linguistic repertoires. As such, it is not always clear to a speaker what listeners might understand in which language. Furthermore, Sandra was required to express herself in her (and most other students') weakest school language, German, which did not allow her to express herself as detailed as she would have been able to by using a wider range of languages from her linguistic repertoire. Thus, in order to bridge possible understanding gaps for the listeners and in order to express her thoughts more fully, it was meaningful to use verbal and nonverbal means of expression. Both served equally important roles in supporting mutual understanding among the interlocutors. She frequently used concrete gestures that added an additional layer of meaning to the verbal to facilitate her plurilingual audience's understanding. This also demonstrated Sandra's embodied engagement in science, which was much deeper than only her verbal means of expression would suggest. Further, analysis of the nonverbal revealed additional layers of understanding regarding how she socially collaborated with her peers in the co-construction of the concept of sustainability. Therefore, it was only through analysis of the verbal and nonverbal that we could see a fuller picture of her conceptual understanding, her linguistic awareness in a multilingual environment, and her social collaboration skills.

In conclusion, both the visual and visual/audible analysis of the video allowed us to slip into the role of a listener who does not fully understand the verbal means of communication as well as a speaker, who is not able to use a wide range of her linguistic repertoire. This perspective allowed us to background Sandra's verbal means of expression and concentrate on what her nonverbal expressions communicated. In this way, we were able to see how students who are not fluent in the languages of instruction could follow everything Sandra said and also how Sandra could express more than she was able with words in a monolingual manner alone, due to the intermingling of meanings produced with the verbal and nonverbal means of expression. In this way, this episode underscores how the nonverbal serves as a powerful tool in multilingual contexts both for listeners as well as for speakers.

\section{Results and discussion}

Through the three video episodes presented, which draw from research across different culturally and linguistically diverse educational contexts, we demonstrate how classroom video analysis rooted in embodied, multimodal analytical approaches reveals both verbal and nonverbal resources used for communication, participation, and meaningmaking. Specifically, we detailed the analysis of three video episodes that each incorporated turning the sound off at different points in analysis, and which revealed resourcerich views of students and teachers interacting in the context of multilingual science classrooms. This approach to video analysis has the power to expose communicative 
resources often masked by analysis that prioritizes verbal productions. In doing so, we have been able to expand the notion of voice in ways that are more equitable in that they include key aspects of nonverbal communication.

The advantages of video analysis when coupled with the methodologies we draw upon in the analysis detailed in this article are multiple. First, video recorded from multiple vantage points/perspectives, and in combination with a rich set of multi-layered data provides analytical perspectives that can be captured in no other way. Second, it allows researchers to revisit a moment, and to slow down that moment in time, and through moment-to-moment analysis to consider spatio-temporal factors such as gestures, positions, and gaze in ways that are not possible to visualize without the ability to see and hear the moment over and over again.

While the benefits of video data sources and analysis are evident, there are challenges that accompany the collection and analysis of video data that should be considered. Video recording, storage, processing and analysis are time-consuming processes. This necessitates that researchers are judicious in their consideration of which and how much video to analyze, and make theoretically driven decisions as to the amount of video analysis conducted. Albeit true, we have found that work with video brings the ability to zoom into aspects of students' voices in ways not possible with audio data and learning artifacts alone.

In our work in multilingual classrooms in Luxembourg, the capability to analyze video in the ways we have shown has particular importance in what it reveals about the voice of culturally and linguistically diverse students and teachers. Students learning to interact in classroom-sanctioned languages can be the last to speak up and or out, and might speak less than students who have greater linguistic competence in those languages. This places language-learners at a deficit when viewed through solely linguistic analytic lenses (see for example Bligh 2014; Snell 2013). Our approach works to push the boundaries of such research, in that we employ analytical approaches that help us to better hear the voice of students who are not creating verbal productions, but rather are employing additional communicative forms.

Over time, as we have experienced the richness this approach to video analysis brings to views of students, it has changed how our research group works. Across all of our research projects, we utilize a layer of analysis that involves turning the sound off at different stages. This layer of analysis allows us to see more clearly the embodied ways students move and relate to each other and the materials in their environment. It reveals the gestures and actions they use to assist them as they work in languages they have not yet mastered. This layer of analysis with the sound off is crucial as it helps us background our own verbal bias in what is revealed when we analyze classroom interactions.

In addition, our video analysis methods have been influenced in that we have moved to seek out theoretical lenses that elaborate the interrelated nature of the body, space, voice, communication, materials and interaction. Our work no longer assumes, as is assumed in much of science education research, that the embodied supports what is being said, or is a secondary factor in interaction. By comparison, it considers the embodied aspects of voice as essential to participation in science and meaningmaking processes. In sum, what we have shown is that video analysis that supports views of the embodied and multimodal in interaction allows researchers to more fully see and hear the voices of students who are often marginalized because of lack 
of proficiency in the mainstream classroom language(s). With this article we underscore the value of video analysis to reveal these resources in interactions in multilingual classroom contexts.

\section{Conclusions}

The case we present in this article, drawn from multiple research projects in our multilingual context in Luxembourg, has implications for research and classroom practices. For researchers, our work suggests specific analytical steps that can lead to broadened views of resources used in communication and interaction in classroom contexts. We suggest how video analysis, coupled with multimodal analysis with the sound off provides insight into communicative resource use by students who tend to be marginalized by verbal-based forms of data analysis. Our work points the way for the future use of these theoretical orientations and analytical techniques to further explore how students employ these resources in communication, and in learning contexts. It affords us the ability to conduct research that examines contextualized interactions in educational contexts, and to connect this with frameworks that critically examine students' voices and their place in classrooms. It valorizes the use of both the non-verbal and the verbal in students' communicative repertoires, and supports viewing and conceptualizing these as tool boxes full of resources, versus seeing them as students lacking the ability to verbally communicate in classroom sanctioned languages.

While the data we present comes from our specific national context in Luxembourg, it has implications for researchers worldwide in that it widens views of students, communication, interaction, and voice in ways that are applicable to all contexts, even those that are seemingly monolingual. More specifically, this article shows how the use of video analysis provides resource-rich views (Siry, 2011) of students. We have shown how video analysis methodologies that incorporate the embodied and multimodal reveal the resources of students who are the first to be marginalized (language-learners, those who are less strong/competent in the classroom sanctioned languages) and how these students engage interactive, spatial, and embodied resources in ways that demonstrate their participation and understanding. Thus, our goal with this paper is to underscore video analysis methodologies that contribute to resource-rich views of students and interactions in classroom contexts.

Lastly, this work has implications for teachers and educators, in that it points to the use of pedagogical practices, such as those highlighted in the projects we draw from (inquiry-based science instruction, project-based, issue-based, rooted in socio-scientific issues) in ways that afford students spaces to engage a wide range of communicative resources, and thus metaphorically, increase the forms of voice they are able to engage while learning, discussing, and demonstrating their understanding.

\section{Endnotes}

${ }^{1}$ For a more detailed explanation of the project see Wilmes 2017a, b.

${ }^{2}$ Pseudonyms have been assigned to retain anonymity.

${ }^{3}$ For a more detailed explanation of the project see Gómez Fernández and Siry 2018. 


\section{Funding}

This research was supported in part by an Aide à la Formation Recherche (AFR) grant (No. 4832121) from the Fonds National de la Recherche (FNR) Luxembourg. Further support was received from a University of Luxembourg faculty grant; Science Education, Innovation, and Policy in Modern Luxembourg (SciPol: Lux).

\section{Availability of data and materials}

The data will not be shared at this time to ensure the anonymity of the participants given that it spans three separate research projects, some of which are still ongoing.

\section{Authors' contributions}

All four authors played an equal part in conducting the research presented, conceptualizing, drafting, reviewing, and preparing this manuscript for publication. All authors read and approved the final manuscript.

\section{Competing interests}

The authors declare that we have no conflicts of interests or competing interests with the research we present in this manuscript.

\section{Publisher's Note}

Springer Nature remains neutral with regard to jurisdictional claims in published maps and institutional affiliations.

Received: 20 December 2017 Accepted: 1 May 2018

Published online: 31 May 2018

\section{References}

Ali-Khan C, Siry C (2014) Sharing seeing: Exploring photo-elicitation with children in two different cultural contexts. Teaching and Teacher Education 37:194-207. https://doi.org/10.1016/j.tate.2013.08.004

Bligh C (2014) The silent experiences of young bilingual learners: a sociocultural study into the silent period. Springer, Netherlands. https://doi.org/10.1007/978-94-6209-797-1

Cameron D, Frazer E, Harvey P, Rampton MBH, Richardson K (1992) Researching language: issues of power and method. Routledge, London

Creese A (2008) Linguistic ethnography. In: Duff P, Hornberger NH (eds) Encyclopedia of language and education, research methods in language and education, vol 10. Kluwer, Dordrecht, pp 229-241. https://doi.org/10.1007/9780-387-30424-3_257

Denzin N (1970) Strategies of multiple triangulation. In: Denzin N (ed) The research act in sociology: a theoretical introduction to sociological method. Butterworth, London, pp 297-313

Derry SJ, Pea RD, Barron B, Engle RA, Erickson F, Goldman R, Sherin BL (2010) Conducting video research in the learning sciences: guidance on selection, analysis, technology, and ethics. J Learn Sci 19(1):3-53. https://doi.org/10. 1080/10508400903452884

Dörnyei Z, Kormos J (1998) Problem-solving mechanisms in L2 communication. Stud Second Lang Acquis 20(03):349-385 https://doi.org/10.1017/s0272263198003039

Elmesky R (2015) Video selection and microanalysis approaches in studies of urban science education. In: Milne C, Tobin K, DeGennaro D (eds) Sociocultural studies and implications for science education, pp 95-115. https://doi. org/10.1007/978-94-007-4240-6_5

Erickson F (2017) Conceiving, noticing, and transcribing multi-modality in the study of social interaction as a learning environment. Linguist Educ 41:59-61. https://doi.org/10.1016/j.linged.2017.07.001

European Commission/EACEA/Eurydice (2017) Key data on teaching languages at School in Europe. In: Eurydice report, 2017th edn. Publications Office of the European Union, Luxembourg

García O (2009) Bilingual education in the 21st century: a global perspective. Wiley/Blackwell, Oxford

Goffman E (1981) Forms of talk. University of Philadelphia Press, Philadelphia

Goldin-Meadow S (2005) Hearing gesture: how our hands help us think. Harvard University Press, Cambridge

Gómez Fernández R, Siry C (2018) Opening up'a science task: an exploration of shifting embodied participation of a multilingual primary student. International Journal of Science Education. 2018 Apr 14:1-25. https://doi.org/10.1080/ 09500693.2018.1447709

Hwang S, Roth WM (2011) Scientific \& mathematical bodies: the interface of culture and mind, vol 22. Springer, Netherlands. https://doi.org/10.1007/978-94-6091-567-3

Jaipal K (2010) Meaning making through multiple modalities in a biology classroom: a multimodal semiotics discourse analysis. Sci Educ 94(1):48-72. https://doi.org/10.1002/sce.20359

Jewitt C (ed) (2009) The Routledge handbook of multimodal analysis. Routledge, London

Kress G (2009) Multimodality: a social-semiotic approach to contemporary communication. Routledge, London

Kress G, Jewitt CO, Ogborn JJ, Tsatsarelis C (2001) Multimodal teaching and learning: the rhetorics of the science classroom. Continuum, New York

Kress G, Ogborn J, Martins I (1998) A satellite view of language: some lessons from science classrooms. Lang Aware 7(2-3):69-89

Lévi-Strauss C (1966) La pensée sauvage. Plon, Paris 1962

Lincoln YS, Guba EG (1985) Naturalistic inquiry. Sage, Beverly Hill

Ministère de l'Éducation nationale, de l'Enfance et de la Jeunesse (MENJE) (2017) Les chiffres clés de l'éducation nationale: Statistiques et indicateurs 2015/2016. http://www.men.public.lu/fr/actualites/publications/themestransversaux/statistiques-analyses/chiffres-cles/2015-2016/index.html. Accessed 10 Dec 2017 
Ministère de l'Éducation nationale et de la Formation professionnelle (MENFP) (2011) École fondamentale: Plan d'études, Luxembourg. http://www.men.public.lu/catalogue-publications/themes-transversaux/cen/cens/planetudes/fr.pdf. Accessed 12 June 2017

Moyer MG (2008) Research as practice: linking theory, method, and data. In: Wei L, Moyer MG (eds) The Blackwell guide to research methods in bilingualism and multilingualism, pp 18-31. https://doi.org/10.1002/9781444301120.ch2

Norris S (2004) Analyzing multimodal interaction: a methodological framework. Routledge, New York. https://doi.org/10. 4324/9780203379493

OECD (2018) The resilience of students with an immigrant background. OECD Publishing. https://doi.org/10.1787/ 9789264292093-en

Pink S (2002) Doing visual ethnography. Sage, New York. https://doi.org/10.4135/9780857025029

Ramos S, Espinet M (2013) Expanded agency in multilingual science teacher training classrooms. In: Mansour AM, Wegereif R (eds) Science education for diversity, Theory Pract. Springer, New York, pp 251-271. https://doi.org/10. 1007/978-94-007-4563-6_12

Siry C (2011) Exploring the significance of resource-rich views in science education. Cultural Studies of Science Education 6 (4):1019-1029.

Siry C, Ziegler G, Max C (2012) "Doing science" through discourse-in-interaction: Young children's science investigations at the early childhood level. Science Education, 96(2), 311-326. https://doi.org/10.1002/sce.20481

Siry C, Max C (2013) The collective construction of a science unit: Framing curricula as emergent from kindergarteners' wonderings. Science Education, 97(6):878-902. https://doi.org/10.1002/sce.21076

Snell J (2013) Dialect, interaction and class positioning at school: from deficit to difference to repertoire. Lang Educ 27:110-128. https://doi.org/10.1080/09500782.2012.760584

Tobin K (2012) Sociocultural perspectives on science education. In: Fraser B, Tobin K, McRobbie C (eds) Second international handbook of science education, pp 3-17. https://doi.org/10.1007/978-1-4020-9041-7

Vertovec S (2007) Super-diversity and its implications. Ethnic Racial Stud 30(6):1024-1054. https://doi.org/10.1080/ 01419870701599465

Wertsch JV (1994) The primacy of mediated action in sociocultural studies. Mind Cult Act 1(4):202-208. https://doi.org/ 10.1080/10749039409524672

Wilmes SED (2017a) Science Workshop: Let Their Questions Lead the Way. In Oliveira O and Weinburgh M (Eds) Science Teacher Preparation in Content-Based Second Language Acquisition (pp. 323-340). Springer, Netherlands

Wilmes SED (2017b) Student-driven Inquiry-based Science Education in Luxembourg Primary School Contexts. Doctoral dissertation, University of Luxembourg, Esch-sur-Alzette, Luxembourg

Wilmes SED and Siry C (in press) Interaction Rituals and Inquiry-based Science Instruction: Analysis of student participation in small-group investigations in a multilingual classroom. Science Education.

Wilmes SED, Siry C, Gómez Fernández R, Gorges A (2018) Reconstructing Science Education within the Language Science Relationship. In L. Bryan \& K. Tobin (Eds.), 13 Questions: Reframing Education's Conversation: Science. New York, NY: Peter Lang, pp 253-266. https://doi.org/10.3726/b11305

\section{Submit your manuscript to a SpringerOpen ${ }^{\circ}$} journal and benefit from:

- Convenient online submission

- Rigorous peer review

- Open access: articles freely available online

- High visibility within the field

- Retaining the copyright to your article 